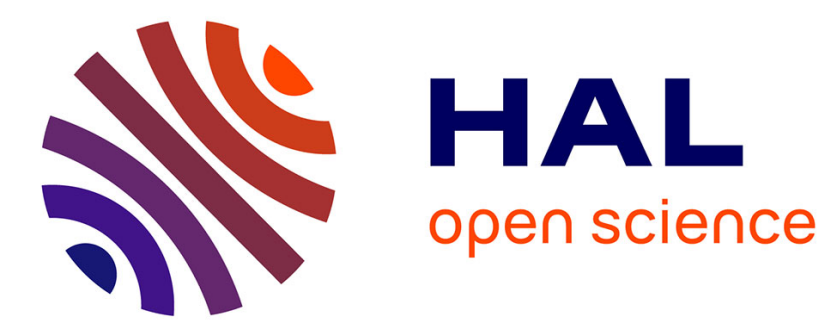

\title{
Olfactory stimulation or inhibition of sexual behavior of stallions in non-breeding season
}

Daniel Guillaume, Chantal Moussu, Frédéric de Geoffroy, Didier Chesneau, Matthieu Keller

\section{- To cite this version:}

Daniel Guillaume, Chantal Moussu, Frédéric de Geoffroy, Didier Chesneau, Matthieu Keller. Olfactory stimulation or inhibition of sexual behavior of stallions in non-breeding season. Physiology \& behavior, 2018, 186, pp.1-9. 10.1016/j.physbeh.2017.12.031 . hal-02625384

\section{HAL Id: hal-02625384 \\ https://hal.inrae.fr/hal-02625384}

Submitted on 26 May 2020

HAL is a multi-disciplinary open access archive for the deposit and dissemination of scientific research documents, whether they are published or not. The documents may come from teaching and research institutions in France or abroad, or from public or private research centers.
L'archive ouverte pluridisciplinaire HAL, est destinée au dépôt et à la diffusion de documents scientifiques de niveau recherche, publiés ou non, émanant des établissements d'enseignement et de recherche français ou étrangers, des laboratoires publics ou privés. 


\section{Accepted Manuscript}

Olfactory stimulation or inhibition of sexual behavior of stallions in non-breeding season

Daniel Guillaume, Chantal Moussu, Frédéric de Geoffroy, Didier Chesneau, Matthieu Keller

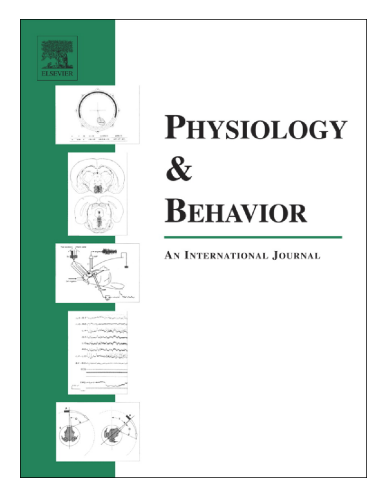
PII:
S0031-9384(17)30460-2
DOI: doi:10.1016/j.physbeh.2017.12.031
Reference: PHB 12025
To appear in: Physiology \& Behavior
Received date: 3 October 2017
Revised date: 19 December 2017
Accepted date:
24 December 2017

Please cite this article as: Daniel Guillaume, Chantal Moussu, Frédéric de Geoffroy, Didier Chesneau, Matthieu Keller, Olfactory stimulation or inhibition of sexual behavior of stallions in non-breeding season. The address for the corresponding author was captured as affiliation for all authors. Please check if appropriate. Phb(2017), doi:10.1016/ j.physbeh.2017.12.031

This is a PDF file of an unedited manuscript that has been accepted for publication. As a service to our customers we are providing this early version of the manuscript. The manuscript will undergo copyediting, typesetting, and review of the resulting proof before it is published in its final form. Please note that during the production process errors may be discovered which could affect the content, and all legal disclaimers that apply to the journal pertain. 
Olfactory stimulation or inhibition of sexual behavior of stallions in non-breeding season

Daniel Guillaume ${ }^{1,2,3,4}$, Chantal Moussu ${ }^{1,2,3,4}$, Frédéric De Geoffroy ${ }^{5}$, Didier Chesneau ${ }^{1,2,3,4}$ \& Matthieu Keller ${ }^{1,2,3,4}$

Affiliation:

1/ INRA, UMR85 Physiologie de la Reproduction et des Comportements, Nouzilly, France

2/ CNRS, UMR7247 Physiologie de la Reproduction et des Comportements, Nouzilly, France

3/ Université François Rabelais de Tours, Tours, France

4/ IFCE, Nouzilly, France

5/ Ecole supérieure du Cheval et de l'Equitation, IFCE, Exmes, France

Short title: olfactory stimulation of stallion sexual responses

Key Words: horses, flehmen, sexual behavior, odors, steroids

Corresponding author: dguillaume@inra.fr 


\section{Abstract}

Stallions show decreased sexual responses and activities during short days in winter. To evaluate the importance of sexual olfactory communication in horses, we tested whether sexual responses could be stimulated through various sexual olfactory stimulations in winter. To this end, we presented stallions with various olfactory stimulations (urine from mares at different stages of the reproductive cycle, urine from stallions or geldings, or chemically defined synthetic odorant) during the non-breeding season and measured their behavioral responses through (1) a test of olfactory investigation (olfactory investigation and flehmen behavior) and (2) a test of sexual activity in the context of semen collection for artificial insemination. It appears that the duration of olfactory investigation and flehmen behavior is longer after presentation of urine (stallion, gelding, anestrous, diestrous and estrous mare) than after presentation of water or synthetic odorant. By contrast, geldings showed reduced flehmen behavior that did not differ from that after water presentation. It is of interest that during the mounting test, mare estrous urine was associated with significantly reduced latency to ejaculation when spread in the nostril of the stallion, compared to anestrous mare urine or water. Anestrous mare urine seems to even inhibit stallion sexual motivation as measured through a longer latency to reach mounting and ejaculation. It appears therefore that during the season of sexual rest, stallion sexual motivation can be stimulated by mare estrous urine and inhibited by mare anestrous urine. These results also suggest that the physiological state of the mare influence the content of urinary chemosignals. 


\section{Introduction}

Horses are seasonal mammals with a breeding season occurring during long days followed by a non-breeding season occurring during short days. This seasonal effect is marked in mares which stop ovulating from November to May under natural conditions in the northern hemisphere [1]. In stallions, this seasonal effect is also present, and Pickett et al. [2] (1976) observed that the volume of the ejaculate, the total number of spermatozoa, and the percentage of gel in the seminal plasma significantly decrease in winter. However, the main effect of season remains a marked decrease of sexual responses, measured either by the preference expressed by stallion towards mares before the beginning of copulation or by the number of mounts needed to reach ejaculation [2].

When in breeding season, horses use various sensory cues to assess the reproductive status of their sexual partner such as auditory, visual, or olfactory cues [3-5]. In stallions, olfactory communication seems to be one of the mechanisms involved in the assessment of the reproductive status of mares. In this context, mare urine is believed to be an important source for signaling estrus and encourages the stallion's pursuit [6-9].

Once in contact with urinary semiochemicals, stallions express flehmen behavior which is characterized by the curling back of the upper lip accompanied with deep inhalations and exhalations $[5,10]$. Flehmen behavior is mostly expressed by stallions. Indeed, castration seems to reduce flehmen expression in geldings, although this was so far only evidenced in a small number of animals $(n=3)$ [11]. However, the role of flehmen behavior to assess female reproductive status is not very clear. Indeed, although the highest frequency of flehmen behavior expressed by stallions is observed around copulation in a group of horses at pasture, this behavior is not discriminative of the reproductive status of the females during presentation of urine or feces from females under various reproductive statuses $[5,11]$. 
Several years ago, studies using gas chromatography clearly demonstrated that the composition of mare urine varies between estrous and diestrous stages [12]. Indeed, when in estrous, mare urine expresses chemical compounds that vary either quantitatively or qualitatively in comparison to the diestrous stage. Furthermore, it has been reported that smearing estrous mare urine on geldings or on nonestrous females triggers mounting and copulation in stallions [13]. Although this result suggests that estrous urine could enhance stallion sexual motivation, definitive proof is still lacking.

In this context, different research groups using gas chromatography coupled with mass spectrometry have recently identified some volatile molecules in mare urine or dung, which seems to be produced in higher amounts around ovulation and therefore to be characteristic of estrus. Nielsen et al [14] (2011) identified 5 carboxylic acids in the feces of three different species of estrous females, including the horse. A mix of these 5 acids induces penile erections in sexually trained male rats. However, this solution was not tested on stallions, and it is therefore not known whether such compounds have any behavioral impact on stallion sexual motivation. More recently, the same group has observed increased frequencies of penile erection in sexually naïve and experienced rats after an exposition to 6-methyl-5hepten-2-one, but it appeared later that this ketone may not be completely specific for estrus $[15,16]$. Another group showed an increase of the $\mathrm{m}$ - and $\mathrm{p}$-cresols in the dung and urine of mares during the estrous phase [17]. When p-cresol was added to diestrous dung, it increased the extent of stallion erections in comparison with diestrous dung alone [18]. However, no proper definitive test evaluating sexual behavior was performed by these authors. In other species, particularly bovine, a mixture of synthetic molecules previously identified in cows' estrous urine was used to investigate the biological effects on male sexual behavior and sperm production. The mixture significantly lowered the bulls' mounting reaction time and ejaculation time (Le Danvic et al 2015) [19]. It was noted that in this mixture, neither one of 
the 5 carboxylic acids [14] nor the ketone [16] nor the P-cresol [18] are present. On the other hand, the Propanoic acid (= propionic acid), which was found to be specific to cow estrus by Sankar and Archunan [20], was also present in the mixture of 5 carboxylic acids [14]

As a whole, these data highlight the absence of any proper demonstration of a positive behavioral effect of estrus-dependent olfactory cues on sexual behavior in stallions. In this context, our experiments were designed to further explore the olfactory and sexual behavior of stallions in response to urine or putative synthetic urinary chemosignals. Therefore, the first aim of our experiments was to test the olfactory behavior of stallions in response to the presentation of various types of urine and putative (chemically defined) synthetic odorant. We also compared these results to those obtained in geldings (castrated males) to properly assess the importance of the physiological status of stallions in the expression of olfactory behavior. Then, the second aim was to properly test whether stallion sexual responses could be stimulated with urine from mares under various reproductive status. Given the already high sexual activity observed in stallions during their sexual season, we tested those animals during their natural season of sexual rest to highlight any potential stimulatory effect. 


\section{Materials and methods}

We conducted 7 different experiments on 5 different sites in France (in Amboise and Nouzilly (Centre Val-de-Loire), in Hennebont and Lamballe (Brittany), and in Le Pin (Normandy). These experiments consisted first of a series of tests in which we presented various odors to stallions (Le Pin presentation test: Le Pin PT) or geldings (Amboise PT) in their boxes. We then performed different mounting tests (mounting tests: Nouzilly1 MT and Nouzilly2 MT over two consecutive years, Brittany MT, Le Pin MT) in association with selected urines (mainly estrous and anestrous mare urine).

\section{Animals and experimental conditions}

The experiment in Nouzilly was conducted on Welsh pony stallions (Equus caballus) of the experimental herd from the National Institute of Agronomic Research (INRA, latitude $47.54^{\circ} \mathrm{N}$ ) in accordance with national animal ethics requirements (French Ministry of Agriculture). The stallions had mean ages of $9 \pm 0.2$ years (mean $\pm S E M)$ and $7.3 \pm 0.1$ years, in the first and second experimental years, respectively. In the other tests, stallions and geldings from the professional schools and studs of the French Institute of Horses and Riding (IFCE) in Le Pin (latitude $48.75^{\circ} \mathrm{N}$ ), Amboise (latitude $47.41^{\circ} \mathrm{N}$ ), Hennebont (latitude $47.80^{\circ} \mathrm{N}$ ), and Lamballe (latitude $48.47^{\circ} \mathrm{N}$ ) were used. In the olfactory presentation and mounting tests in Le Pin (Le Pin PT), we tested 12 light horses (taken from: 4 Anglo-Arabian horses, 2 French Saddle Horses, 6 French Trotters, 2 foreign Saddle Horses) with a mean age of $14.8 \pm 0.03$ years. In Amboise (Amboise PT), the mean age of the 10 Anglo-Arabian geldings was $5.8 \pm 0.5$ years, and the age at castration was $1.7 \pm 0.2$ years (ranging from 1 year old to 3 years old). In Brittany (Brittany MT, i.e. in Hennebont and in Lamballe), a total of 18 stallions of a local draft horse breed, the "Trait Breton," was used. In Lamballe, 6 sexually experienced stallions $(8.5 \pm 1.4$ years old $)$ and 6 young stallions $(2.5 \pm 0.3$ years old $)$ were used. These young stallions had just begun to be trained for collection on the dummy 
and were therefore considered to have a low level of sexual experience. The groups allowed for comparison based on sexual experience and age. Finally, in Hennebont, the six stallions, all experienced, had a mean age of $11 \pm 2$ years old.

All the stallions were in good body condition (body condition score of around 3 on a scale ranging from 1 (thin) to 5 (obese) except in Amboise where the geldings has a body condition score of around 2. In all these locations, housing and nutritional conditions were quite similar. Animals were housed individually in boxes with free access to water and mineral salt. They were fed with hay complemented with commercial pellets and had access to a paddock 3 hours per day. Except for the 6 young Breton stallions in Hennebont, all the stallions were routinely used for semen collection procedures to perform artificial insemination. The semen collection procedures followed the guidelines of the French national stud [21].

The olfactory substrates used for the presentation tests were urine, artificial (chemically defined) odors, or water, the latter serving as a negative control. Mare urine was previously collected from 8 pony mares in the INRA herd. In summer, these mares were monitored daily through transrectal ovarian ultrasonography throughout an entire estrous cycle, from ovulation to ovulation. The urine of these mares was collected every day, just after ultrasonography, with a urinary probe (length $40 \mathrm{~mm}$ diameter $8 \mathrm{~mm}$, Vygon ORX 00042008) inserted into the urethra. In December, when these 8 mares were in winter ovarian inactivity, anestrous urine was also collected. In stallions and geldings, kept in the INRA herd at Nouzilly, urine was collected through natural urination. After collection, urine was quickly put in glass vials, frozen with dry ice and kept at $-20^{\circ} \mathrm{C}$. The urine of 3 mares in the same physiological state or 3 stallions or 3 geldings was mixed and aliquoted by $5 \mathrm{ml}$ in glass vials, and these mixtures were frozen at $-20^{\circ} \mathrm{C}$ until use. This method ensured good conservation of urinary compounds, as demonstrated for urinary steroids by Laparre et al. [22] (2017). 
Finally, testosterone was measured on blood samples to check for the physiological status of geldings and stallions that were used either for providing urinary stimuli or as experimental animals (i.e. no detectable testosterone level in geldings and normal testosterone level in stallions).

Regarding synthetic odorant, we tested several substrates. First, we tested the fatty acid mixture, which was published as being characteristic of female estrus and has shown to induce erection in male rats [14]. These fatty acids (propanoic acid, 2-methylpropanoic acid, butanoic acid, 3-methylbutanoic acid and pentanoic acid) were obtained from Sigma-Aldrich (Saint Quentin Fallavier, France) and were dissolved in MilliQ water at a final concentration of $0.1 \%(\mathrm{v} / \mathrm{v}), 0.033 \%, 0.12 \%, 0.11 \%$, and $0.16 \%$, respectively. The other artificial odor was p-cresol which has been shown to be more abundant in mare estrous urine [17]. The stallions' response to -p-cresol was compared to their response to o- and $\mathrm{m}$-cresol at the same concentration. These cresols (Sigma) were prepared at a concentration of $130 \mu \mathrm{g} / \mathrm{ml}$ [17].

For the test of odor presentation, $5 \mathrm{ml}$ of odorant substrate (after warming at $35^{\circ} \mathrm{C}$ ) was spread on a surgical gauze which was then placed in a box with a stainless steel wire mesh cover $\left(18 \times 18 \mathrm{~cm}\right.$ with 16 holes $/ \mathrm{cm}^{2}$; each hole has a diameter of $\left.1.5 \mathrm{~mm}\right)$ to prevent direct physical contact with the odor source. The test of odor presentation was performed on stallions in Le Pin (Le Pin PT) in January. Each of the 9 odors was presented to each of the 12 stallions in a randomized order for the first presentation (split-plot design). These 9 odors came from the urine of mares in estrus or in anestrus, from the urine of stallions or geldings, from synthetic odorant (o-, m-, p-cresols, fatty acids), and from a negative control (water). In Amboise (Amboise PT), tests were performed on geldings; only the 4 of urine and the water were used.

For the mounting test in Nouzilly (Nouzilly1 MT and Nouzilly2 MT), the 6 stallions were kept in individual boxes, located in the same building as the room in which they were 
tested for mounting. A quantity of $5 \mathrm{ml}$ of odorant was spread in the nostrils of the stallions while they were in their boxes. The behavior of each stallion was then immediately filmed for three minutes. At the end of this period, each stallion was then led to the mounting room. In the mounting room, the inseminator and the groom collected semen from the stallion (without the presence of mares) following the French professional guidelines [21]. The test lasted 10 minutes. Both parts of the test were video-recorded. The 6 stallions received 3 types of odor (water as a negative control, and estrous and anestrous urine) in a Split-Plot design on three separate days with one presentation per week. This experiment was repeated twice, at a one-year interval, under the same conditions. However, at one site (Nouzilly2 MT), 2 stallions were used only the first year and were replaced by 2 others stallions the second year, so 4 stallions were used over a one-year interval.

This experiment was adapted in Brittany (Brittany MT) and Le Pin (Le Pin MT). In Brittany MT, the odor was spread in the stallions' nostrils in a neighboring stable in front of the mounting room. The 18 Breton stallions (12 experienced and 6 young stallions) received 6 types of odors in a Split-Plot design on 6 different dates during a 2-week period at the end of autumn. These 6 odors came from the urine of estrous, diestrous, and seasonal anestrous mares, of geldings, and of stallions, and from water, which served as a negative control. In Le Pin MT, 3 types of odors were presented to the 12 light horse stallions. The odors came from the urine of estrous or anestrous mares or from water, spread in the nostrils. In addition, estrous mare urine was also presented under a wire mesh as in Le Pin PT. This last group allowed us to compare stallion behavior when treated with mare estrous urine that was directly accessible physically and when that urine was not directly accessible physically.

\section{Behavioral analysis:}

For the experiments in Le Pin PT and Amboise PT, we measured flehmen and sniffing (olfactory investigation) occurrences and durations. For the mounting tests (Nouzilly1 MT, 
Nouzilly2 MT, Brittany MT, Le Pin MT) we measured the total duration of flehmen behavior, in the box and in the mounting room, latency to obtaining the first full erection, duration of the full erection, latency to $1^{\text {st }}$ mount on the dummy, and latency to ejaculation. The test ended when ejaculation occurred. Ejaculation was defined as the moment when the stallion was mounted on the dummy, in erection, showing a characteristic movement of the rump and tail followed by the confirmation of ejaculation by the inseminator who handles the artificial vagina.

All tests were filmed. Videos of the first experiments (Le Pin PT, Amboise PT) were blindly analyzed by 2 independent experimenters. Due to the marked correlations between the results obtained (minimum correlation for flehmen duration and ejaculation latency: $\mathrm{r}^{2}=0.82$ and $\mathrm{p}<0.0001)$, the mean of their results was used for statistical analysis.

On the basis of these results, the following experiments (mounting test: Nouzilly1 MT, Nouzilly2 MT, Brittany MT and Le Pin MT) were analyzed by only one experimenter with the help of a specific software program for behavioral analysis (BORIS, Behavioral Observation Research Interactive Software; [23]) developed by the University of Torino (Italy). First, we tested whether the use of this software provides results similar to those obtained previously. As results were highly correlated with those obtained manually with a stopwatch on Nouzilly1 MT (minimum correlation for flehmen behavior duration and ejaculation latency: $r^{2}=0.74$ and $\left.p<0.004\right)$, only the results obtained with BORIS were used for statistical analysis. In these tests, when erection, mounting the dummy, and ejaculation were not observed within the 10-minute duration of the test, latency was counted as 10 minutes.

\section{Semen analysis:}

When stallions reached ejaculation, the semen was collected with the artificial vagina. Gel fraction was removed by filtration through gauze, and volume was measured. Sperm 
concentration was evaluated using a photometer (IMV Technologies, France), as previously described [21]. In the absence of a photometer at Hennebont, this measure was not performed.

\section{Testosterone assays:}

After each urine collection in summer, from geldings and from stallions (3-4 samples/animal) and at the end of each behavioral test in winter, (1 sample/animal), blood samples were collected from the jugular vein to measure plasma testosterone and thereby verify the sexual status of the animals. Testosterone was assayed with RIA without extraction, developed in our laboratory, adapted for horses from a previous publication regarding rams [24]. The main cross-reactions were with dihydrotestosterone (43\%), androstenediol (4\%), androstenedione (4\%), and androstanediol (3\%). The intra- and inter-assay coefficients of variation were systematically lower than $10 \%$. The quantification limit was $0.125 \mathrm{ng} / \mathrm{ml}$. The variability of this assay for a reference of $0.5 \mathrm{ng} / \mathrm{ml}$ was $4 \%$.

\section{Statistical analysis:}

All the parametric statistical tests were carried out using SAS software (SAS Institute Inc., Cary, NC 27513, USA). For the various types of video analysis, the correlation between the results obtained by the experimenters was estimated (proc corr in SAS). The duration and latency, expressed in seconds, were analyzed after $\log (x+1)$ transformation with the aim of normalizing the curve of frequency distribution as suggested by Dagnelie [25] (1998). For the mounting test (Nouzilly1 MT, Nouzilly2 MT, Brittany MT, Le Pin MT), the flehmen behavior duration in the first 3 minutes of the test (presentation in the box) was compared via analysis of variance using the general linear model (GLM) procedure. The error term for the treatment effect was the interaction treatment*stallion. This specific procedure for a split plot design was adapted from Dagnelie [25] (1998). Furthermore, the 3 common treatments (estrous and anestrous urine, and water) during the various mounting tests were pooled and analyzed as described above. In the case of the 2 tests conducted in Nouzilly, the 4 stallions (out of 6 animals) that were tested twice over two consecutive years (Nouzilly 1 MT and Nouzilly 
2 MT) were considered different individuals.

When the $1^{\text {st }}$ erection, $1^{\text {st }}$ mount on the dummy, and ejaculation were not observed during the test, latency was counted as the maximum of the test duration (600 s). For these latencies and to overcome the hypothesis of normal repartition of the data, the analysis was performed using proc Glimmix in SAS, adapted to the Latin square design following Piepho et al., [26] (2015). The effects of treatment, date, and their interactions were included in the model as fixed effects and the stallions as random effect.

For the endocrine level, only the comparison on the pony stallions, in Nouzilly, between summer and winter was done after $\log (x+1)$ transformation, by ANOVA using the general linear model (GLM) procedure with a procedure adapted for repeated data [27].

Statistical differences were declared significant at $\mathrm{p}<0.05$ and trends at $\mathrm{p}<0.10$. Results are reported as arithmetical means \pm SEM. 


\section{$\underline{\text { Results: }}$}

\section{Presentation tests in Le Pin and in Amboise (Le Pin PT, Amboise PT):}

In the Le Pin PT experiment, all stallions were immediately interested in the olfactory stimulus and expressed sniffing behavior. Once stimulated with urinary odors, sniffing was immediately followed by the expression of flehmen, and alternation of sniffing and flehmen behavior lasted several minutes. It is of interest that during the expression of flehmen, stallions produce a few milliliters of nasal secretion, as previously described by Lindsay et al [10] (1983). The total durations of sniffing and flehmens behaviors as well as the number of flehmen responses are shown in Figure 1 for Le Pin PT and Amboise PT.

The stallions showed more sniffing-flehmen sequences (sniffing duration, flehmen responses, and flehmen response duration) after being presented with urine compared to water. Among the various presentations of urines, sniffing-flehmen sequences were more numerous and total duration of sniffing or flehmen during the 10-minute test were longer after being presented with stallion urine compared to gelding urine. The effects of presentations of synthetic odorant (cresols and fatty acids) were not significantly different from the effects of presentations of water.

In Amboise (Amboise PT), the number and duration of sniffing or flehmens responses expressed by geldings were very low regardless of the olfactory stimulus. The comparison between the stimuli are therefore not significant for the different variables (global effect of the treatments on duration of sniffing and duration of flehmens responses were $p=0.9$ and $p=0.3$ respectively). It is also interesting to note as well that all the variables were very low in comparison to those found in stallions (Le Pin PT).

\section{Mounting test (Nouzilly1 MT, Nouzilly2 MT, Brittany MT, Le Pin MT):}

In the Brittany MT, the young (and therefore poorly sexually experienced) horses were 
collected on only one occasion out of 36 trials. If we compare the 6 young stallions and the 6 old stallions (and therefore more experienced) at the same place (Lamballe), in the mounting room, across all treatments, latency to erection, first mounting of the dummy, and ejaculation were longer for the younger stallions $(\mathrm{p}=0.017, \mathrm{p}=0.049, \mathrm{p}=0.023$ respectively). Furthermore, four young stallions had very low testosterone levels $(<0.4 \mathrm{ng} / \mathrm{ml}$, see Figure 4$))$. Based on these results, all the young stallions were removed from statistical analyses of the behavioral testing described below.

During the $1^{\text {st }}$ part of the test (urinary stimulation in the box) and for the 4 experiments (Le Pin MT, Brittany MT, Nouzilly 1 \& 2 MT) in which urine was spread on the nostrils (or sniffed through the wire mesh in Le Pin), there was an immediate flehmen response. At each site, the effect of the treatment was globally highly significant for the duration of the flehmen behavior during the 3 -minute period $(\mathrm{p}<0.005$, see table 1$)$. Furthermore, the 2-by-2 comparisons indicate that these durations were significantly longer when different types of urine were presented to the stallion, compared to water (in all the experiments $\mathrm{p}<0.05$ ), but no difference among the different types of urine was observed. In the Le Pin MT experiment, the difference between the effects of the 2 types of estrous urine presentations (spread in the nostril or under an iron wire mesh) were not significantly different $(\mathrm{p}=0.20)$.

In the second part of the test, in the mounting room, differences were observed with regard to latency to erection according to the type of odors presented (see table 1). In Brittany MT, the anestrous and diestrous urine had the same effect and induced a longer latency to erection than water $(\mathrm{p}=0.0028$ and $=0.0013$ respectively) or estrous urine $(\mathrm{p}<0.0001$ in the 2 cases); by contrast the effect of water or mare estrous urine were not different $(p=0.74)$. In this experiment, the effect of stallion urine was not different from anestrous or diestrous mare urine or water $(\mathrm{p}=0.39, \mathrm{p}=0.24, \mathrm{p}=0.24$ respectively). The effect of gelding urine was not different from the other urinary odors. In Le Pin MT and Nouzilly1 MT, the effects of 
treatment on erection latency were not significant. In Nouzilly2 MT, the global effect of the treatment was significant $(\mathrm{p}=0.007)$, and the effect of estrous treatment was lower than that of anestrous treatment $(\mathrm{p}=0.006)$ and tended to be lower than that of water $(\mathrm{p}=0.050)$. When combining all the experiments across common treatments (water, estrus, and anestrus), the differences among the 3 treatments were significant $(\mathrm{p}<0.0001$; Figure 2$)$, and latency to erection after estrous urine treatment was significantly shorter than after anestrous urine $(\mathrm{p}<0.0001)$, but the difference after estrous urine treatment compared to after water treatment did not reach significance $(\mathrm{p}=0.11)$.

When analyzing latency to $1^{\text {st }}$ mount in Brittany MT, the treatment with anestrous and diestrous mare urine had the same effect and induced a longer latency to $1^{\text {st }}$ mount than the treatment with water $(\mathrm{p}=0.012$ and 0.015 respectively $)$ or estrous mare urine $(\mathrm{p}<0.0001$ in the 2 cases). Latency to $1^{\text {st }}$ mount was not significantly shorter after mare estrous urine treatment than after water treatment $(\mathrm{p}=0.34)$. In this experiment, the effect obtained after stallion urine treatment was not significantly different from anestrous and diestrous mare urine $(p=0.17$ and 0.21 respectively) and not different from water $(\mathrm{p}=0.82)$. Gelding urine induced significantly shorter latency to 1 st mount than anestrous and diestrous mare urine $(p=0.015, p=0.019$ respectively), but the effect did not differ from that of stallion urine $(\mathrm{p}=0.29)$ or estrous urine $(p=0.29)$. In Le Pin MT, the effects of treatments were not significant $(p=0.8)$, but the results suggest that latency to $1^{\text {st }}$ mount was higher with anestrous urine. In the Nouzilly1 MT experiment, there was a tendency towards shorter latency to mount after estrous urine treatment than after anestrous urine treatment $(\mathrm{p}=0.11)$. In the second Nouzilly experiment, latency to $1^{\text {st }}$ mount was significantly shorter with mare estrous urine compared to mare anestrous urine $(\mathrm{p}=0.04)$ and tended to be shorter compared to water $(\mathrm{p}=0.10)$.

When combining the results of all the experiments (Brittany MT, Le Pin MT, Nouzilly $1 \& 2 \mathrm{MT}$ ), the differences among the 3 common treatments (water, estrous, and anestrous 
treatments), latency to mount the dummy was significantly longer after anestrous urine treatment than after water or estrous urine treatment $(\mathrm{p}=0.04$ and $\mathrm{p}<0.0001$ respectively). A tendency was noted for the latency to erection to be shorter after estrous urine treatment than after water, control treatment $(\mathrm{p}=0.087)$.

Regarding the latency to ejaculation in Brittany MT, the effects of treatments were not significant, but the results appeared to be similar to those for the previous events in this test (latency to erection or mounting). In Le Pin MT, the effects of treatments were significant: the anestrous mare urine systematically delayed ejaculation compared to all other treatments $(\mathrm{p}<0.001)$, but the 2 treatments with mare estrous urine had no significant effects compared to water. In Nouzilly1 MT and in Nouzilly2 MT, a tendency was observed for estrous mare urine to shorten the latency to ejaculation compared to anestrous mare urine $(\mathrm{p}=0.08$ and $\mathrm{p}=0.06$ respectively). When combining the data from all the experiments, for the 3 common treatments (water, estrus, and anestrus), the differences among these 3 treatments became highly significant $(\mathrm{p} \leq 0.0002$; Figure 2$)$.

\section{Semen analysis}

Out of the 3 common treatments (anestrous and estrous mare urine and water) across all sites, treatment appeared significant only for semen volume and not for spermatozoa concentration ( $\mathrm{p}=0.017$ and $\mathrm{p}=0.36$ respectively; Figure 3 ). Unfortunately, due to the unbalanced number of ejaculates analyzed, the two-by-two comparisons of LSmeans could not be performed on the volume but the estrous urine treatment seems to have no effect. The mean concentration of spermatozoa for the three common treatments was $341 \pm 2910^{6}$ spermatozoa/ml.

\section{Hormone levels}

The hormone level results are shown in Figure 4. Geldings tested for behavioral responses in Amboise PT or used for urine collection in Nouzilly presented levels of plasma 
testosterone under the sensitivity limit of the assay, thus confirming the efficiency of castration. The difference between each category of horse was globally different $(p<0.0001)$. For stallions used in Nouzilly PT and Nouzilly1 MT, the difference between seasons appeared to not be significantly different (estimation based on only one blood sample in winter). In Brittany MT, 4 out of 6 young stallions had very low plasma testosterone levels $(<0.4 \mathrm{ng} / \mathrm{ml})$, but the difference compared to older Breton stallions was not significant. 


\section{Discussion:}

In this manuscript, we provide clear results regarding olfactory regulation of male sexual behavior in stallions in response to urinary cues. Although this question was previously investigated in the past, the conclusions obtained were limited due to a very low number of animals used $(\mathrm{n}=2-4)$. Here, we performed tests on a large number of animals in five studs with similar management procedures and show for the $1^{\text {st }}$ time that olfactory investigation of mare estrous urine is stimulatory for stallion sexual behavior in winter while anestrous urine is inhibitory.

In stallions, the duration and number of sniffing and flehmen behaviors are higher with urine presentation than with water presentation. We note a marked variation between each stallion on flehmen response. For example, after stallion urine presentation, the flehmen duration varied from $8 \mathrm{~s}$ to $187 \mathrm{~s}$ during the $600 \mathrm{~s}$ of the test. The fact that some sniffing was observed when water was presented could be related to the novelty of the iron wire mesh under which stimuli were presented in the box of the animals. However, this sniffing was never followed by the expression of flehmen behavior. By contrast, presentation of urine induced a high level of olfactory investigation and flehmen behavior. It is of interest that stallions seem to not show differences in flehmen response (duration or number) between estrous mare urine, anestrous mare urine, and gelding urine. These results are largely in line with those described by Stahlbaum \& Houpt [5] (1989). However, those authors also reported, in a semi-natural situation, an increase of the rate of flehmen responses around the day of copulation with mares in 2 stallions, suggesting a potential olfactory discrimination of the female's reproductive state. However, it is possible that other sensory stimuli emitted by the mares in estrus could provide synergistic information for males being responsible for differences based on whole animals instead of urine only. It is also possible that in more natural conditions, the expression of flehmen behavior is more specific. However, the low 
number of animals observed associated with the variability inherent to any behavioral study in semi-natural conditions renders any statistical comparison very difficult.

In summer at the moment of urine collection, the testosterone level in pony stallion samples appeared significantly higher than in the blood collected from light horse or Breton stallions in winter after behavioral testing. This is in accordance with the increases in plasma testosterone level which was induced by a photostimulating treatment [28].

Flehmen behavior expressed by stallions is greater after sniffing stallion urine than after sniffing gelding urine. Here, the stallion and gelding urine came from Welsh ponies bred in Nouzilly, so the difference cannot be attributed to differences in horse management (feeding, location, etc.) or breed. Therefore, the differences observed between the responses induced by gelding and stallion urine is due to differences in physiological status which induced different concentrations in circulating sexual steroids. Such differences can directly (excretion of conjugated sexual steroids in the urine) or indirectly modify urine composition. It is clear that testosterone, which is the main sexual steroid in males, could be the main circulating hormone responsible for such an effect. However, a role for other steroids should not be discarded; for example, in stallions, plasma estrone concentration is very high, between 100 to $300 \mathrm{ng} / \mathrm{ml}$, around 100 times higher than testosterone or estradiol levels [29, 30]. This leads to very high excretion of sulfated estrone in urine.

In Amboise PT, the testosterone plasma level found in geldings was under the detection limit of our assay thus confirming that these horses were efficiently castrated. These animals expressed a low level of olfactory investigation which was not differentiated according the type of urinary stimulation. Geldings also express flehmen behavior, but this is a very rare event. Flehmen behavior occurrs in colts early in life (1-4 weeks old) or before puberty [6]. In mares, male-like behaviors including mating and flehmen responses can be observed and are associated with a high plasma testosterone level [31]. The difference 
between stallions and geldings fully confirms that olfactory investigation and especially, flehmen response to urinary odors is expressed following the activator effect of testosterone in adulthood. A similar conclusion has been obtained in males goats [32], but in our study the time between castration and our experiment $(4.2 \pm 0.5$ years; means \pm SEM) was longer than those reported by Hart and Jones [32] in goats. Those authors observed a 20 percent decrease in flehmen behavior after female urine presentation after 41-52 weeks of castration. This explains the marked reduction in, but not total disappearance of, flehmen behavior in our experimental geldings.

It is of interest that no difference in flehmen behavior was observed when the stallions had direct access to urine compared to when the stimulus was covered by a wire mesh (Le Pin PT). These results suggest that the semiochemicals involved in the induction of flehmen behavior and the subsequent mounting response are at least partly volatile in nature. In mice, it has been classically demonstrated that both volatile and non-volatile olfactory signals can interact in olfactory communication [33].

Finally, in stallions, the sniffing and flehmen behavior duration did not differ between water and the various putative semiochemicals tested (mix of fatty acids, p-cresol). This suggests that those chemicals cannot stimulate stallion sexual responses, at least alone. Various possibilities exist to explain our negative results. it is $1^{\text {st }}$ possible that these compounds have a synergistical action with other neutral compounds present in urine that need to be simultaneously present so that the compounds used become active. In this case, it would be necessary, for example, to present the compound in another medium such as in the urine of a ovariectomized mare. In this case, the stimulating odor for stallions is probably a more complex olfactory bouquet. It is also possible that these chemicals are behaviorally inactive. Indeed the mix of five fatty acids tested by Nielsen et al. [14] (2011) in rats is not at all predictive of its behavioral significance in stallions. In addition, the behavioral evaluation 
of p-cresol on ejaculation intensity is rather limited and probably highly variable [18]. Pcresol glucuronide and p-cresol sulfate are normally present in horses urine [34]. However, in human, it has been demonstrated that p-cresol is formed from bacterial degradation of tyrosine and is subsequently sulfated or glucuronidated in the liver or gut [35] and therefore not directly influenced by physiological state. In all the cases, it is clear that the identification of precise semiochemicals controlling stallion response remains an open question.

Once having established the effect of urinary odors for the stimulation of stallion olfactory behavior, we tested whether the same sexual odors (especially estrous and anestrous urine) stimulate stallion responses during the season of sexual rest. In line with the results described previously, flehmen behavior was immediately expressed following urinary stimulation within the nostrils of stallions, independent of the physiological stage of the mare urine used. No differences were observed with regard to the duration and number of flehmen responses according to the type of urine used (estrous mare vs anestrous mare). By contrast, no or very little sniffing and flehmen behavior was expressed when stallions were stimulated with water, thus strongly confirming the results obtained during the $1^{\text {st }}$ experiment related to odor presentation.

Once in the mounting room, flehmen behavior was decreased, whereas erection, mounting, and ejaculation occurred. Despite some variability according to the breed of animal used or the location of the experiment (and therefore animal management), latencies of erection, mounting on the dummy, and ejaculation were significantly shortened when stallions were stimulated by estrous mare urine compared to water or anestrous urine. For these experiments we have used a split-plot experimental design which is not classically used in behavioral research. In this design the undesirable effects including such as the place in which the horses are kept or the breed, are controlled and confound, in the statistical analyze with the "animal effect"; so the statistical significance of the treatment effects cannot be biased. 
Furthermore, in each of the 4 experiments, during the mounting test, the different latencies were shorter after the estrous urine treatments and longer after anestrous urine treatments. When the 4 experiments are pooled together, the effect of anestrous mare urine was also statistically inhibitory in comparison to water and estrous urine. The volume of ejaculate appeared higher after estrous urine treatment than after anestrous urine treatment. This result confirms the difference of sexual activity after the 2 treatments.

The anestrous mare urine was collected in December (i.e., not in spring during the transition phase), a time when neither progesterone nor ovarian estrogens can be detected in the plasma. Therefore, urinary signals are clearly related to the physiological status of the emitter and are obviously dependent upon circulating sex steroids levels. The steroiddependent semiochemicals (possibly the steroids themselves, as they could act as chemosignals) present in estrous urine could be a key signal for the expression of sexual behavior by the stallion. The absence of these specific semiochemical(s) would be a signal explaining the difference compared to water and anestrous urine. However, the fact that anestrous urine is also inhibitory should lead us to consider the possibility that inhibitory substances can be also present in winter anestrous mare urine and/or that stallion nervous systems respond differently to chemosignals due to seasonal regulations. For example, it has been shown in mice that a juvenile pheromone produced by young mice before puberty, exocrine-gland secreting peptide 22 , is secreted from the lacrimal gland and released into the tears of 2- to 3-week-old mice. This chemosignal inhibits sexual behavior towards juveniles [36].

Another interesting point to mention is that the 6 young Breton stallions tested in Lamballe widely differed from their adult and more sexually experienced conspecifics. The fact that the two groups were tested in exactly the same place and conditions allows us to discard any side effects due to animal management or any other confounding bias. These 
absence of effect of estrous mare urine to stimulate the young horses is in accord with Gonzalez et al [37] (1991) who observed than in inexperienced rams the LH increase after the presentation of receptive ewes is lower than in experimented rams. This result therefore suggests that sexual experience (although this parameter cannot be disentangled from age) makes the animal more responsive to female olfactory stimuli and makes such stimuli more efficient to induce sexual response (i.e. mounting behavior in the conditions used for sperm collection).

When analyzing the two experiments (presentation of urinary odors and stimulation of sexual behavior), it is striking to notice that both types of urine (estrus and anestrus) induce high levels of flehmen behavior but that the sexual response varies considerably, with estrous urine inducing a stimulatory response and anestrous urine inducing an inhibitory response. While it is clear that the expression of the flehmen response is specific to social (here, urinary) stimulation, it is not at all predictive of the nature of the behavioral response. Therefore the flehmen response cannot be classified as a sexual response, especially as it is known in horses (but also in other ungulates) and as it occurs in other social contexts, appearing as both juvenile behavior and maternal behavior [6, 38].

Finally, in field conditions, sport horse stallions are more available for semen collection in winter before riding competitions, which start in spring. Furthermore, the freezing capacity of semen appears to be better in winter than in summer. This is probably due to the difference in plasma seminal composition which presents a low rate of gel in winter [2, 39]. In winter, the majority of mares are in anestrus [1]; therefore, the use of fresh mare urine, which has an inhibitory effect on stallion sexual motivation, should be avoided to facilitate sperm collection. By contrast, the use of frozen estrous urine collected during the previous summer constitutes a good method to stimulate the sexual motivation of stallions for semen collection during the sexual rest season. 


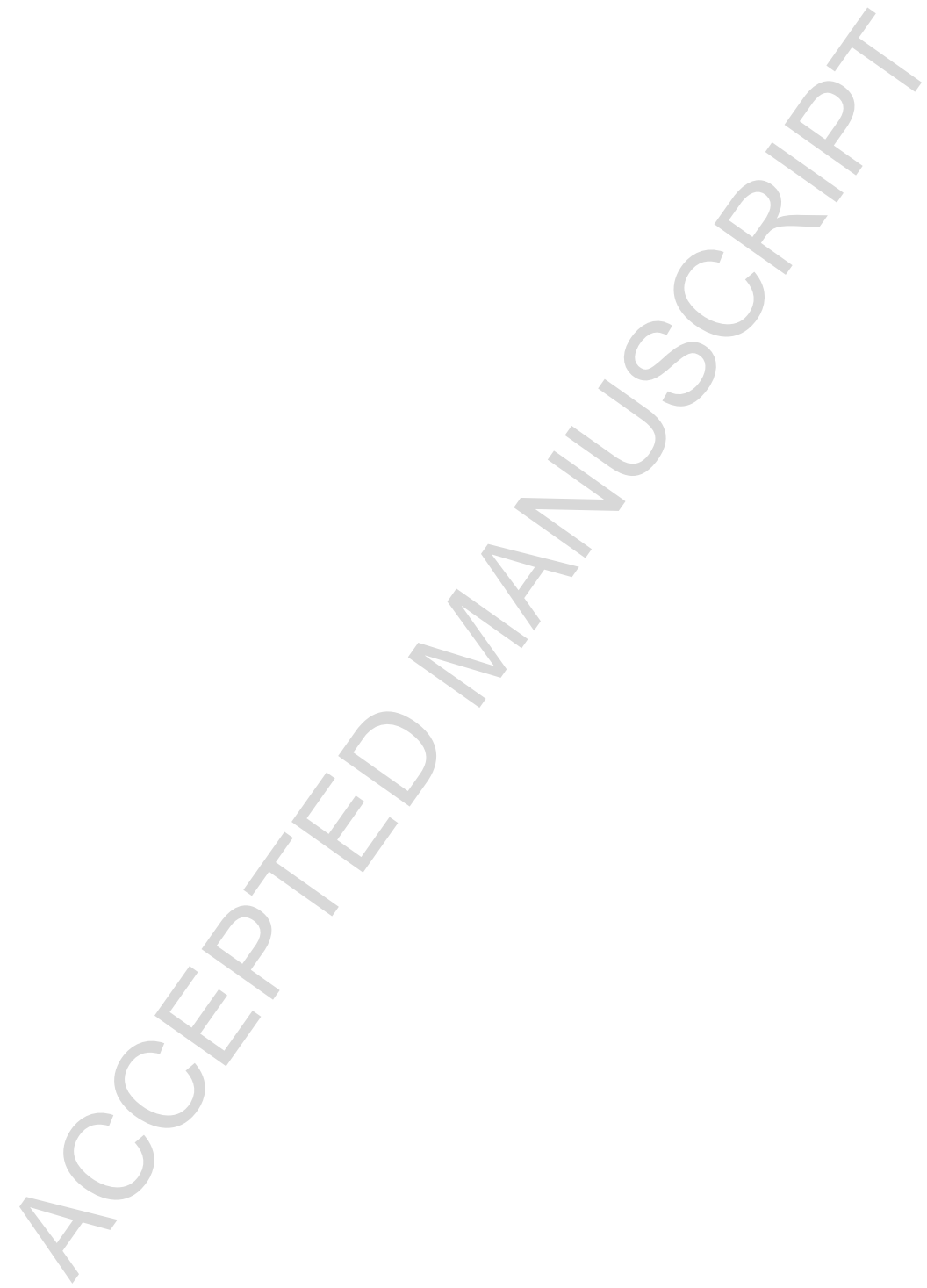




\section{References}

[1] Salazar-Ortiz, J., Camous, S., Briant, C., Lardic, L., Chesneau, D., Guillaume, D. Effects of nutritional cues on the duration of the winter anovulatory phase and on associated hormone levels in adult female Welsh pony horses (Equus caballus). Reprod Biol Endocrinol. 2011,9:130.

[2] Pickett, B. W., Faulkner, L. C., Seidel, G. E., Jr., Berndtson, W. E., Voss, J. L. Reproductive physiology of the stallion. VI. Seminal and behavioral characteristics. J Anim Sci. 1976,43:617-25.

[3] Crowell-Davis, S. L. Sexual behavior of mares. Horm Behav. 2007,52:12-7.

[4] Lemasson, A., Remeuf, K., Trabalon, M., Cuir, F., Hausberger, M. Mares prefer the voices of highly fertile stallions. PLoS One. 2015,10:e0118468.

[5] Stahlbaum, C. C., Houpt, K. A. The role of the Flehmen response in the behavioral repertoire of the stallion. Physiol Behav. 1989,45:1207-14.

[6] Crowell-Davis, S., Houpt, K. A. The ontogeny of flehmen in horses Animal Behaviour. 1985,33:739-45.

[7] Fraser, A. F. Reproductive behaviour in ungulates. London and New York: Academic Press ed 1968.

[8] Kiley-Worthington, M. Behavioural problems In: M K-W, ed. The behaviour of horses in relation to management and training: JA Allen, London, UK; 1987. p. 189-215.

[9] Tembock, G. Animal Communication. Ed TA Seboek. Indiana University Press, Bloomington. 1968:338404.

[10] Lindsay, F. E., Burton, F. L. Observational study of "urine testing" in the horse and donkey stallion. Equine Vet J. 1983,15:330-6.

[11] Marinier, S., Alexander, A., Waring, G. Flehmen behaviour in the domestic horse: discrimination of conspecific odours. Applied Animal Behaviour Science. 1988,19:227-37.

[12] Ma, W., Klemm, W. R. Variations of equine urinary volatile compounds during the oestrous cycle. Vet Res Commun. 1997,21:437-46.

[13] Hafez, E., Wierzbowski, S. Analysis of copulatory reflexes in the stallion. Proceeding of the IV ${ }^{\text {th }}$ International congress of animal reproduction. La Hague 1961. p. 176-9.

[14] Nielsen, B. L., Jerome, N., Saint-Albin, A., Thonat, C., Briant, C., Boue, F., et al. A mixture of odorant molecules potentially indicating oestrus in mammals elicits penile erections in male rats. Behav Brain Res. 2011,225:584-9.

[15] Nielsen, B., Jerôme, N., Saint-Albin, A., Ouali, C., Rochut, S., Zins, E. L., et al. Estrus odours from rats and mares: Behavioural responses of sexually naive and experienced rats to natural odours and odorants. Applied Animal Behaviour Science. 2016,176:128-35.

[16] Nielsen, B. L., Jerome, N., Saint-Albin, A., Rampin, O., Maurin, Y. Behavioural response of sexually naive and experienced male rats to the smell of 6-methyl-5-hepten-2-one and female rat faeces. Physiol Behav. 2013,120:150-5.

[17] Mozuraitis, R., Buda, V., Kutra, J., Borg-Karlson, A. K. p- and m-Cresols emitted from estrous urine are reliable volatile chemical markers of ovulation in mares. Anim Reprod Sci. 2012,130:51-6.

[18] Buda, V., Mozuraitis, R., Kutra, J., Borg-Karlson, A. K. p-Cresol: a sex pheromone component identified from the estrous urine of mares. J Chem Ecol. 2012,38:811-3.

[19] Le Danvic, C., Gerard, O., Sellem, E., Ponsart, C., Chemineau, P., Humblot, P., et al. Enhancing bull sexual behavior using estrus-specific molecules identified in cow urine. Theriogenology. 2015,83:1381-8.

[20] Sankar, R., Archunan, G. Gas chromatographic/mass spectrometric analysis of volatile metabolites in bovine vaginal fluid and assessment of their bioactivity. Int J Anal Chem. 2011,2011:256106.

[21] Haras-Nationaux. Insémination artificielle équine. 5 ed. 61310 Le-Pin au Haras: Institut Français du Cheval et de l'Equitation; 2014.

[22] Laparre, J., Kaabia, Z., Mooney, M., Buckley, T., Sherry, M., Le Bizec, B., et al. Impact of storage conditions on the urinary metabolomics fingerprint. Anal Chim Acta. 2017,951:99-107.

[23] Friard, O., Gamba, M. BORIS: A free, versatile open-source event-logging software for video/audio coding and live observations. Methods in Ecology and Evolution. 2016,7:1327-30.

[24] Hochereau-De Reviers, M., Copin, M., Seck, M., Monet-Kuntz, C., Cornu, C., Fontaine, I., et al. Stimulation of testosterone production by PMSG injection in the ovine male: effect of breed and age and application to males carrying or not carrying the "F" Booroola gene. Animal Reproduction Science 1990,23:2132.

[25] Dagnelie, P. Statistique théorique et appliquée. Inférence statistique à une et à deux dimensions. Bruxelles: De Boeck \& Larcier S.A. ; 1998.

[26] Piepho, H., Williams, E., Michel, V. Beyond Latin Squares: A brief tour of raw-column designs. Biometry, Modeling \& statistics. Agronomy Journal. 2015,107:2263-70. 
[27] Little, R., Henry, P., Ammerman, C. Statistical Analysis of repeated measures data using SAS procedures. Journal of Animal Sciences 1998,76:1216-31.

[28] Thompson, D. L., Jr., Pickett, B. W., Berndtson, W. E., Voss, J. L., Mett, T. M. Reproductive physiology of the stallion. VIII. Artificial photoperiod, collection interval and seminal characteristics, sexual behavior and concentrations of LH and testosterone in serum. J Anim Sci. 1977,44:656-64.

[29] Kaabia, Z., Dervilly-Pinel, G., Hanganu, F., Cesbron, N., Bichon, E., Popot, M. A., et al. Ultra high performance liquid chromatography/tandem mass spectrometry based identification of steroid esters in serum and plasma: an efficient strategy to detect natural steroids abuse in breeding and racing animals. J Chromatogr A. 2013,1284:126-40.

[30] Villani, M., Cairoli, F., Kindahl, H., Galeati, G., Faustini, M., Carluccio, A., et al. Effects of mating on plasma concentrations of testosterone, cortisol, oestrone sulphate and 15-ketodihydro-PGF2alpha in stallions. Reprod Domest Anim. 2006,41:544-8.

[31] Gastal, M. O., Gastal, E. L., Beg, M. A., Ginther, O. J. Elevated plasma testosterone concentrations during stallion-like sexual behavior in mares (Equus caballus). Horm Behav. 2007,52:205-10.

[32] Hart, B. L., Jones, T. O. Effects of castration on sexual behavior of tropical male goats. Horm Behav. 1975,6:247-58.

[33] Hurst, J. L., Beynon, R. J. Scent wars: the chemobiology of competitive signalling in mice. Bioessays. 2004,26:1288-98.

[34] Escalona, E. E., Leng, J., Dona, A. C., Merrifield, C. A., Holmes, E., Proudman, C. J., et al. Dominant components of the Thoroughbred metabolome characterised by (1) H-nuclear magnetic resonance spectroscopy: A metabolite atlas of common biofluids. Equine Vet J. 2015,47:721-30.

[35] Clayton, T. A., Baker, D., Lindon, J. C., Everett, J. R., Nicholson, J. K. Pharmacometabonomic identification of a significant host-microbiome metabolic interaction affecting human drug metabolism. Proc Natl Acad Sci U S A. 2009,106:14728-33.

[36] Ferrero, D. M., Moeller, L. M., Osakada, T., Horio, N., Li, Q., Roy, D. S., et al. A juvenile mouse pheromone inhibits sexual behaviour through the vomeronasal system. Nature. 2013,502:368-71.

[37] Gonzalez, R., Orgeur, P., Poindron, P., Signoret, J. P. Female effect in sheep. I. The effects of sexual receptivity of females and the sexual experience of rams. Reprod Nutr Dev. 1991,31:97-102.

[38] Levy, F., Keller, M., Poindron, P. Olfactory regulation of maternal behavior in mammals. Horm Behav. 2004,46:284-302.

[39] Magistrini, M., Chanteloube, P., Palmer, E. Influence of season and frequency of ejaculation on production of stallion semen for freezing. J Reprod Fertil Suppl. 1987,35:127-33. 


\section{List of abbreviations:}

GLM = general linear model procedure: an analysis of variance in SAS software

RIA = Radio-immuno-assay

\section{Conflict of interests:}

The authors declare that they have no competing interests.

\section{Authors contributions:}

DG supervised the work, worked on animal experimentation, prepared synthetic odorant, analyzed videos, performed hormonal assays, performed statistical analysis, and wrote the manuscript. FdeG collected stallions and provided all the facilities at Le Pin. CM helped during animal experimentation, prepared urine mixtures, and analyzed videos. DC helped at different stages of animal experimentation. MK helped during animal experimentation and corrected the final manuscript.

\section{Acknowledgements:}

The authors wish to thank L. Le Neun for her help during animal experimentation and video analysis, C. Sanjuan for video analysis, J. Berthier for help during urine collection. We thank the UEPAO technical staff and especially F. Reigner, Y. Gaudé, P. Barrière, and T. Gascogne for taking care of the horses and for their help during INRA (UEPAO) experiments. We tank V Furtoss and Dr T Ntallaris for their help for SAS programming. We thank A.L. Lainé, D. Genetay, and C. Laclie from the laboratory of hormonal assays of PRC for testosterone assays. We thank I. Couty for her help with sperm analysis. We also thank F. Cuir and J. Courbe for their help with stallions at the Ecole supérieure du Cheval et de l'Equitation, IFCE at Le Pin; C. Briant and S. Lavenant for taking care of the geldings in Amboise; P. Ecot, G. Plongère, D. Le Bec, M. Jacob, J.P. Jourdain, H. Montfort, J. Le Galludec, and A. Letoullec for their help with the Breton stallions. We thank the "syndicat of 
the Traits Bretons" for lending us their stallions. Finally, we tank C Lestè-Lasserre for English language corrections of the manuscript.

\section{Funding:}

This work was supported by INRA's "Physiologie Animale et Systèmes d'Elevage" department and by the "Institut Français du Cheval et de l'Equitation" (IFCE).

\section{Figure captions:}

Figure 1: Results of the Le Pin PT and Amboise PT. The total sniffing and flehmen durations and the number of flehmens during the $10 \mathrm{~min}$ of the teste are presented on the left column for the stallions at Le Pin and on the right column for gelding at Amboise. For the stallions, the global effect of the treatment is significant on these 3 parameters $(\mathrm{p}<0.0001)$. The different treatments are regrouped into homogenous group following Tukey-Kramer test $(\mathrm{p}<0.05)$. The different homogenous groups are indicated with different superscripts. For geldings, the global effect of the treatment is never significant (NS: not significant).

Figure 2: Results of the 5 MT tests pooled on the common treatments (estrous and anestrous urine and water), on the total duration of flehmen during the 3 mins of the $1^{\text {st }}$ part of the test and on the latency to $1^{\text {st }}$ erection, of $1^{\text {st }}$ jump on the dummy and of ejaculation during the 10 mins of the second part of the test (arithmetical means, time in seconds). The statistical signification of the global effect of the treatment is shown in the grey area upper the graph. The significant differences of the effect of each treatment are indicated with different superscripts following Tukey-Kramer grouping $(\mathrm{p}<0.05)$.

Figure 3: Means of the total volume of the ejaculate obtained during the common treatments of 4 mounting tests (estrous or anestrous urine and water). The global effect of the treatment is significant $(\mathrm{p}=0.017)$. The number of stallions for which the volume of ejaculate was measured is indicated in bold characters.

Figure 4: Plasma testosterone levels on experimental animals.

The categories of horses and the number of horses in each categories are indicated in the upper part of the figure: A and B, means of the gelding and stallions in Nouzilly stables which were uses for urine collections in summer; $\mathrm{C}$ and $\mathrm{D}$ means of the gelding at Amboise and stallions at Le Pin which were uses for presentation tests; E mean of the young Breton stallions at Lamballe; F means of old Breton stallions at Lamballe and Hennebont; $G$ mean of light horses used in the mounting tests; $\mathrm{H}$ and I means of Welsh pony stallions used in the mounting test at Nouzilly during the 1 st and 2nd winter. The significant differences between each group of animals are indicated with different lowercase letters following Tukey-Kramer grouping $(\mathrm{p}<0.05)$. 
Table 1: Results of the 5 tests, on the total duration of flehmen during the 3 mins of the first part of the test and on the latency of $1^{\text {st }}$ erection, of $1^{\text {st }}$ jump on the dummy and of ejaculation during the 10 mins of the second part of the test (arithmetical means, time in seconds). The global effect of the treatment is shown in the $2^{\text {nd }}$ column and, when it appeared significant, the 2 by 2 comparisons between Least Squares Means (LSMeans) of each treatment are indicated with different superscript following Tukey-Kramer grouping $(\mathrm{p}<0.05)$.

\begin{tabular}{|c|c|c|c|c|c|c|c|c|}
\hline & $\begin{array}{c}\text { Global } \\
\text { effect of } \\
\text { treatment }\end{array}$ & Water & Anestrus & $\begin{array}{l}\text { Estrus } \\
\text { (In the } \\
\text { nostril) }\end{array}$ & $\begin{array}{c}\text { Estrus } \\
\text { (under } \\
\text { grill) }\end{array}$ & Diestrus & Stallion & Geldings \\
\hline \multicolumn{9}{|c|}{ Bretagne MT } \\
\hline $\begin{array}{c}\text { Total } \\
\text { duration of } \\
\text { flehmens }\end{array}$ & $\mathrm{p}<0.0001$ & $2.4 \pm 0.9^{b}$ & $14.5 \pm 1.4^{\mathrm{a}}$ & $19.6 \pm 5.6^{\mathrm{a}}$ & & $28.2 \pm 5.8^{\mathrm{a}}$ & $11.5 \pm 2.7^{\mathrm{a}}$ & $16.0 \pm 3.7^{\mathrm{a}}$ \\
\hline $\begin{array}{l}\text { Latency of } \\
1^{\text {st }} \text { erection }\end{array}$ & $\mathrm{p}<0.0001$ & $172 \pm 75^{b-}$ & $290 \pm 81^{a}$ & $113 \pm 66^{c}$ & & $290 \pm 78^{a}$ & $\frac{253 \pm 80^{\mathrm{a}^{-}}}{\mathrm{b}}$ & $223 \pm \frac{ \pm 81^{a-}}{b}$ \\
\hline $\begin{array}{c}\text { Latency of } \\
\mathbf{1}^{\text {st }} \text { jump }\end{array}$ & $\mathrm{p}<0.0001$ & $\underset{c}{228 \pm 80^{b-}}$ & $320 \pm 78^{\mathrm{a}}$ & $171 \pm 75^{\mathrm{c}}$ & & $304 \pm 76^{\mathrm{a}}$ & $\underset{b}{264 \pm 78^{a-}}$ & $\underset{\mathrm{c}}{228 \pm 80^{\mathrm{b}-}}$ \\
\hline $\begin{array}{l}\text { Latency of } \\
\text { ejaculation }\end{array}$ & $\mathrm{p}=0.3353$ & $308 \pm 79$ & $381 \pm 74$ & $262 \pm 76$ & & $361 \pm 76$ & $290 \pm 73$ & $293 \pm 70$ \\
\hline \multicolumn{6}{|c|}{ LePin MT } & & & \\
\hline $\begin{array}{c}\text { Total } \\
\text { duration of } \\
\text { flehmens }\end{array}$ & $\mathrm{p}<0.0001$ & $0.36^{\mathrm{b}}$ & $9.6 \pm 6.0^{\mathrm{a}}$ & $9.9 \pm 4.5^{\mathrm{a}}$ & $3.0 \pm 2.1^{\mathrm{a}}$ & & & \\
\hline $\begin{array}{l}\text { Latency of } \\
1^{\text {st }} \text { erection }\end{array}$ & $\mathrm{p}=0.2896$ & $136 \pm 47$ & $274 \pm 68$ & $119 \pm 39$ & $168 \pm 59$ & & & \\
\hline $\begin{array}{c}\text { Latency of } \\
\mathbf{1}^{\text {st }} \text { jump }\end{array}$ & $\mathrm{p}=0.80$ & $204 \pm 65$ & $286 \pm 65$ & $174 \pm 54$ & $221 \pm 67$ & & & \\
\hline $\begin{array}{l}\text { Latency of } \\
\text { ejaculation }\end{array}$ & $\mathrm{p}=0.0001$ & $238 \pm 65^{b}$ & $398 \pm 59^{a}$ & $205 \pm 58^{b}$ & $250 \pm 65^{b}$ & & & \\
\hline \multicolumn{5}{|c|}{ Nouzilly 1 MT } & & & & \\
\hline $\begin{array}{c}\text { Total } \\
\text { duration of } \\
\text { flehmens }\end{array}$ & $\mathrm{p}=0.0006$ & $9.7 \pm 5.6^{\mathrm{b}}$ & $43.7 \pm 9.1^{\mathrm{a}}$ & $60.0 \pm 10.2^{\mathrm{a}}$ & & & & \\
\hline $\begin{array}{l}\text { Latency of } \\
1^{\text {st }} \text { erection }\end{array}$ & $\mathrm{p}=0.1641$ & $448 \pm 100$ & $457 \pm 85$ & $233 \pm 112$ & & & & \\
\hline $\begin{array}{c}\text { Latency of } \\
\mathbf{1}^{\text {st }} \text { jump }\end{array}$ & $\mathrm{p}=0.1147$ & $451 \pm 98$ & $474 \pm 82$ & $242 \pm 113$ & & & & \\
\hline $\begin{array}{l}\text { Latency of } \\
\text { ejaculation }\end{array}$ & $\mathrm{p}=0.0831$ & $478 \pm 78$ & $476 \pm 80$ & $258 \pm 112$ & & & & \\
\hline \multicolumn{5}{|c|}{$\begin{array}{l}\text { Nouzilly } 2 \text { MT } \\
\end{array}$} & & & & \\
\hline $\begin{array}{c}\text { Total } \\
\text { duration of } \\
\text { flehmens }\end{array}$ & $\mathrm{p}=0.005$ & $10.8 \pm 7.0^{\mathrm{b}}$ & $42.8 \pm 7.3^{\mathrm{a}}$ & $31.7 \pm 9.9^{\mathrm{a}}$ & & & & \\
\hline $\begin{array}{l}\text { Latency of } \\
1^{\text {st }} \text { erection }\end{array}$ & $\mathrm{p}=0.007$ & $408 \pm 97^{\mathrm{a}}$ & $533 \pm 67^{\mathrm{a}}$ & $207 \pm 85^{b}$ & & & & \\
\hline $\begin{array}{c}\text { Latency of } \\
\mathbf{1}^{\text {st }} \text { jump }\end{array}$ & $\mathrm{p}=0.0405$ & $\underset{\mathrm{b}}{438 \pm 85^{\mathrm{a}-}}$ & $533 \pm 67^{\mathrm{a}}$ & $242 \pm 85^{b}$ & & & & \\
\hline $\begin{array}{l}\text { Latency of } \\
\text { ejaculation }\end{array}$ & $\mathrm{p}=0.0594$ & $523 \pm 59$ & $587 \pm 13$ & $354 \pm 112$ & & & & \\
\hline
\end{tabular}


Stallions
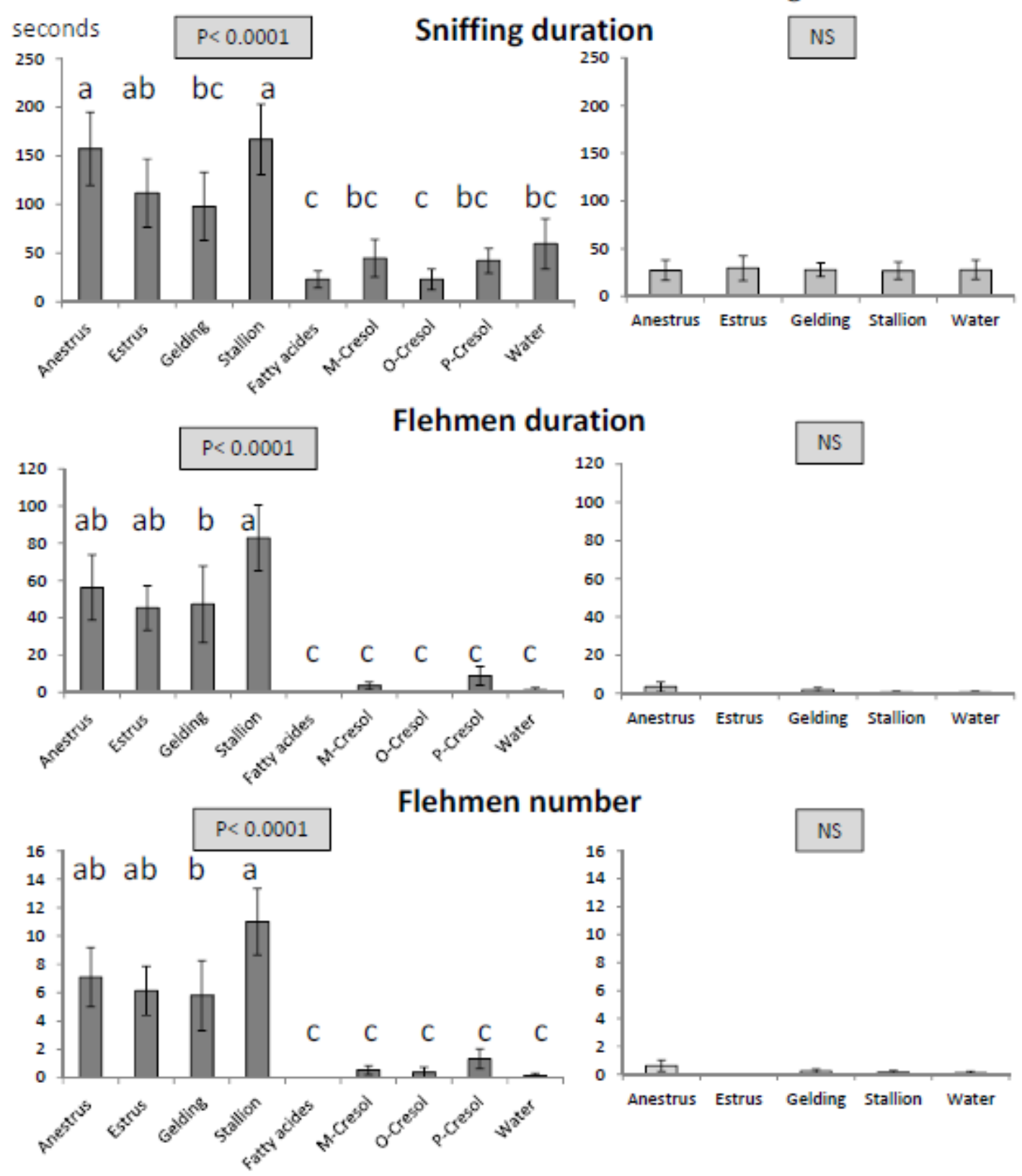


\section{On all the experiments}

Flehmen duration during
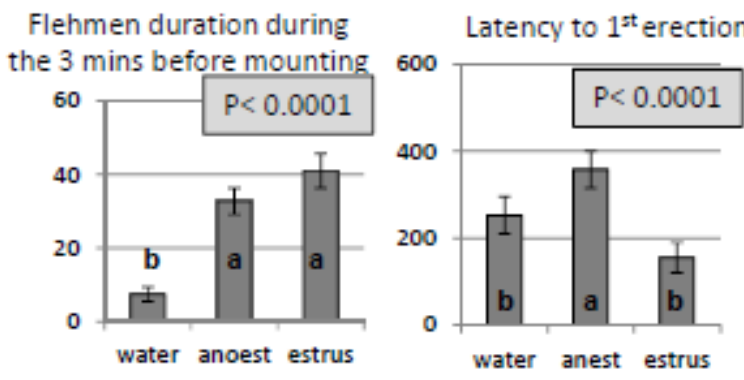

Latency to $1^{\text {st }}$ jump

latency to ejaculation
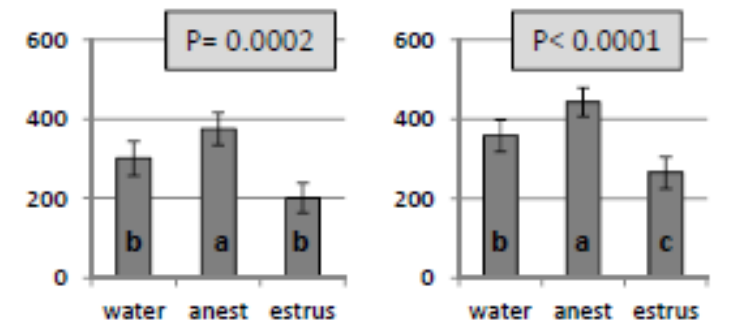

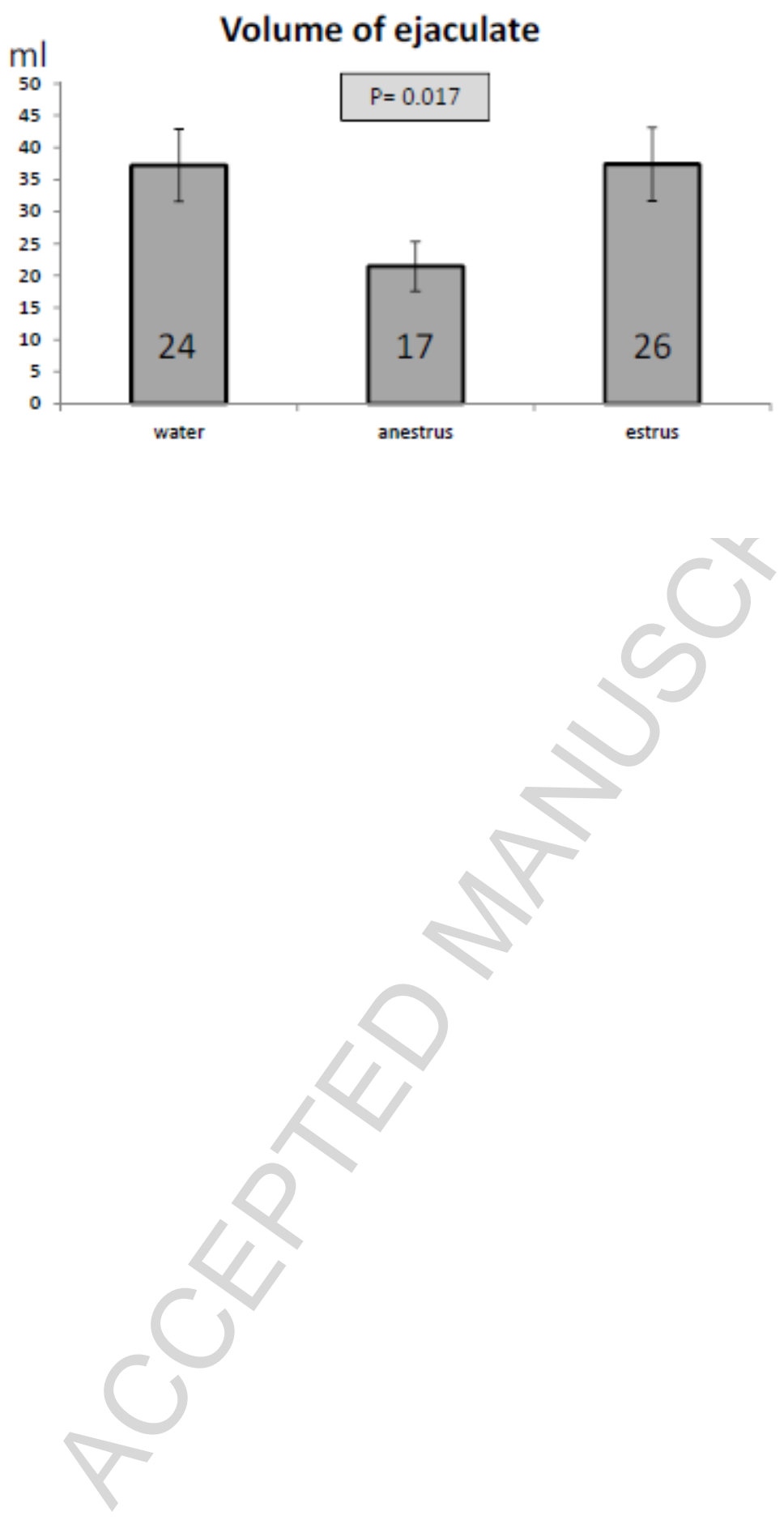


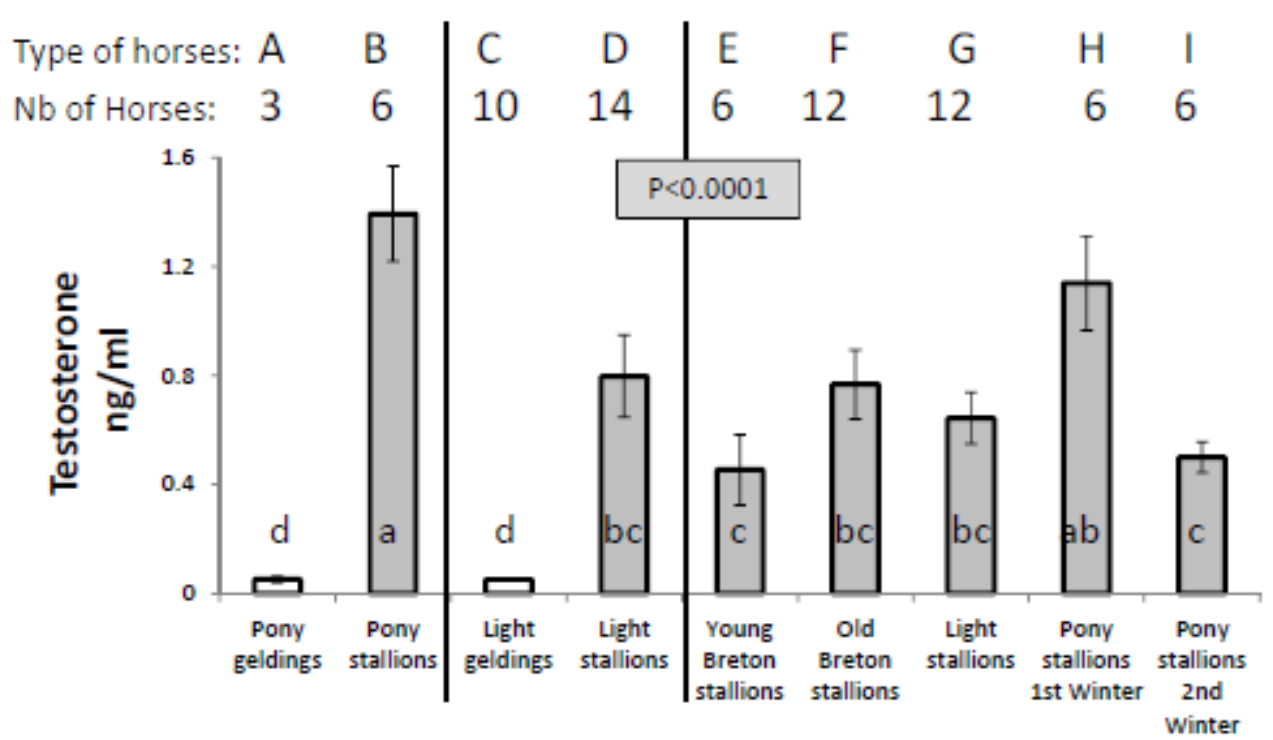


Highlights points:

- No difference, in flehmen behavior by stallion between estrus and anestrus mare urines.

- Chemical compounds previously identified did not induced stallion flehmen.

- Estrus mare urines stimulate stallion sexual motivation during short days (SD).

- Diestrus and Anestrus mare urines inhibit stallion sexual motivation during SD. 